\title{
Fichte: cultura y libertad
}

Hugo Ochoa

\section{OpenEdition}

\section{Journals}

\section{Edición electrónica}

URL: http://journals.openedition.org/ref/577

DOI: 10.4000/ref.577

ISSN: 2258-014X

\section{Editor}

EuroPhilosophie Editions

Referencia electrónica

Hugo Ochoa, «Fichte: cultura y libertad », Revista de Estud(i)os sobre Fichte [En línea], 9 | 2014

Publicado el 28 diciembre 2014, consultado el 08 septiembre 2020. URL : http://

journals.openedition.org/ref/577 ; DOI : https://doi.org/10.4000/ref.577

Este documento fue generado automáticamente el 8 septiembre 2020.

(c) EuroPhilosophie 


\title{
Fichte: cultura y libertad
}

\author{
Hugo Ochoa
}

1 Ha sorprendido a la política establecida, particularmente en Europa, pero no sólo allí, el surgimiento del llamado movimiento "Pirata", movimiento que ha ido sistemáticamente creciendo y ya constituye una fuerza política que no puede ser obviada o desatendida por insignificante, no sólo por su número, sino sobre todo por sus intenciones. Leía hace poco a un comentarista internacional que se mostraba bastante extrañado porque este movimiento no tenía un programa, se entiende un programa de gobierno, ni una estructura organizacional que regulara y regularizara sus propuestas. No obstante, por cierto, esta falta de estructuración es consecuente con sus planteamientos, y poca falta que les hace.

2 Pues bien, ¿qué es lo que pretenden? Su propósito es explícito, me parece, y claro, quieren un espacio público que no esté regido por las reglas del mercado ni por la lógica de la competencia, sino por las de la colaboración y solidaridad, un lugar tal que el afán de lucro no pueda tener lugar, donde los intereses individuales estén efectivamente subordinados a los universales, donde los objetos no sean mercancías y los bienes estén al alcance de cualquiera y beneficien a todos. Apenas surgió este nuevo espacio virtual que, por su misma virtualidad es universal en el sentido más propio, es decir, carece esencialmente de toda frontera, se inició por parte de los poderes establecidos su inmediata colonización; se lo comprendió como una extensión, cuasi natural, del mercado, sólo que ahora en él no se cruzaban sólo algunos caminos, sino que era el cruce de todos ellos, incluso de los todavía no pavimentados. Acciones, bolsa, negocios, transacciones, dinero, empresas, etc., se apoderaron de ese espacio, surgieron monopolios y oligopolios, creadores e imitadores, los bancos y empresas adaptaron sus productos a este espacio y, de este modo, se pretendió suprimir o, al menos, disminuir, la esencial diferencia que hay entre el espacio del mercado tradicional y este nuevo continente; era un espacio económico más, sujeto en definitiva a las mismas reglas. Se intentó evangelizar a sus nativos, originariamente unos ingeniosos ingenieros tal vez no ingenuos, todos jóvenes, con la biblia del desarrollo económico y, sobre todo, con la oportunidad de ganancias repentinas, insólitas y... legales. Esto último es importante, porque ese espacio era originariamente ácrata y había que, rápidamente, establecer allí también las reglas del imperio, con su correspondiente estructura punitiva. Un ámbito 
de pura libertad, más aún, de libertad pura, donde no sólo los objetos, sino también las mismas identidades, la nacionalidad, la raza, el género, están absolutamente abiertos a la libertad, parecía atentar desde sus cimientos contra una concepción radicalmente substancialista del mundo y de los seres humanos.

Aparentemente ya se había renunciado definitivamente a los fundamentos originarios de la sociedad occidental contemporánea, relegándolos al ámbito de la u-topía. Así, pues, al principio, sin que nadie se diera cabal cuenta, surgió una suerte de topos, un lugar no substancial, que yo calificaría por lo mismo de hypertopos, porque así como el hipertexto permite lecturas en todas direcciones, no habiendo ninguna privilegiada, así el espacio virtual carece de centro, de norte, de sur. En este hypertopos sería posible, pues, la libertad, la fraternidad, la igualdad, simples y puras, no negociadas, allí podrían éstas abrirse camino haciendo su propio camino, allí cabrían todas las banderas, cada uno podría tener la suya, cabrían todos los sueños, y no como sueños, y, lo que es más importante, sin que pudiera, aparentemente, establecerse un sistema de vigilancia panóptica y pannómica que pudiera asumir el control imperial de ese espacio.

Se debe tener presente que, en razón de la misma virtualidad del hypertopos, lo que importa a los piratas son los productos cuya virtualidad los hace ser propios de ese espacio, no se trata de bienes materiales cuyo uso exclusivo está determinado por la misma naturaleza del bien, sino de productos cuya inmaterialidad encuentra su espacio más propio y, me atrevería a decir, natural, en la virtualidad. Son bienes cuyo uso no los agota, sino que los deja indemnes, de modo que su propiedad y uso excluyente sólo puede ser mantenido en virtud de una regulación punitiva y, por lo tanto, sólo opera esta propiedad en tanto es reconocida, otorgada, regulada y defendida por parte del Estado; de allí su carácter simbólico. Como sostiene Condorçet:

"No puede haber ninguna relación entre la propiedad de una obra y la de un campo que puede ser cultivado por un hombre, o de un mueble que sólo puede servir a un hombre, cuya propiedad exclusiva, en consecuencia, se encuentra fundada en la naturaleza de la cosa, [...] la propiedad literaria no es un derecho, es un privilegio y como todos los privilegios, es un obstáculo impuesto a la libertad, una restricción evidente a los derechos de los demás ciudadanos". ${ }^{1}$

5 Se trata, pues, dicho en general, de la cultura, del saber, del conocimiento, que ahora (digo "ahora" porque la propiedad intelectual es, en realidad, de reciente data y, me atrevería a decir, es formal y masivamente impuesta con la aparición del capitalismo) constituyen formas de propiedad cuyo valor no es determinable en términos clásicos, por ejemplo, los que proponía el Aquinate, ya que el costo de producción puede ser cero y los beneficios que acarrea inconmensurables, como la invención de la rueda, o de la escritura, para poner ejemplos extremos. De modo que, paradójicamente, la misma propiedad intelectual confirmaría la tesis de que el valor de un producto sólo puede ser establecido por el mercado.

6 La rebelión pirata, entonces, tiene como campo de batalla la cultura misma, entendida ésta en un sentido amplio. Se podrá decir que detrás hay grandes conglomerados cuyos intereses no son la cultura, como firmas farmacéuticas, empresas industriales, marcas, etc., pero los agentes primarios son, en definitiva, los creadores de cultura. Quiero decir que esta rebelión se puede comprender como una revuelta de las masas no creadoras, sino consumidoras, contra una inteligentzia que defiende su estatus basado en un presunto, o no, genio exclusivo y, por lo tanto, excluyente. Se trata, entonces, de una propiedad intelectual que protege productos de la inteligencia, sustentado tanto en un "derecho moral" que protege la paternidad e integridad de la obra o producto, que no 
está en cuestión, como el "derecho de propiedad" propiamente tal, que defiende la obra o producto como patrimonio de uso y transacción exclusivos de su autor.

Más allá de la discusión marxiana acerca del origen y fundamento de la superestructura ideológica, sin duda esta forma de propiedad tiene un estatuto peculiar y distintivo. Se sostiene incluso que el origen de toda riqueza postfeudal tiene su origen en una creación de este tipo, de allí que en su defensa esté en juego la misma lógica originaria del sistema económico moderno. Por ello, como decía, desde la misma constitución de este espacio hypertópico comenzó su colonización. Pero, también se tiene que tener en cuenta que, desde otra perspectiva, este espacio, por su misma universalidad no tópica, podría permitir una vigilancia panóptica que almacenara en archivos clasificados por gustos, vicios, virtudes, intereses, temores, vivencias, ingresos, errores y omisiones, la oscura identidad de cada miembro de este mundo, para venderlo luego al mejor postor. Naturalmente, lo anterior sigue la lógica del mercado en la cual nuestra identidad se inscribe en la dialéctica productor-consumidor. La pregunta que surge inmediatamente es, pues, si acaso es posible una decolonización de este hypertopos.

8 A este respecto, quisiera abordar el problema de la cultura desde la perspectiva de Fichte. Como se sabe, Fichte intentará resolver la aporía de la cosa en sí kantiana, aporía porque si nos preguntamos qué puede ser aquello que no está en el espacio ni en el tiempo, que no es substancia ni accidente, ni causa ni efecto, habrá que confesar que no puede ser $=\mathrm{X}$, como sostiene Kant, sino $=0$, es decir, absolutamente nada. ${ }^{2}$ No obstante, en el conocimiento no nos tenemos por libres en lo que se refiere a su contenido; algunas de nuestras representaciones se hallan acompañadas del sentimiento de libertad, al paso que a otras las acompaña un sentimiento de necesidad. Este sentimiento es el que estaría a la base de la afirmación kantiana por la que se afirma la existencia de la cosa en sí, pues la sensibilidad, pasiva, requiere de una materia dada que se impone. La solución de este problema constituye la tarea de la filosofía. “¿Cuál es la razón de ser del sistema de las representaciones acompañadas de un sentimiento de necesidad, y de este sentimiento de necesidad mismo". ${ }^{3}$

La solución de Fichte está basada en tres principios que constituyen el fundamento de su sistema.

"Aquello cuyo ser (Wesen) simplemente consiste en ponerse a sí mismo como siendo, es el Yo como sujeto absoluto. De la misma manera como él se pone, es; y de la misma manera que es, se pone; y entonces el Yo es necesaria y absolutamente para el Yo. Aquello que no es para sí mismo no es un Yo". ${ }^{4}$

10 La absoluta autoposición del Yo constituye su misma libertad, ${ }^{5}$ en la medida que revela su carácter incondicionado. Así, pues, que el Yo se ponga absolutamente a sí mismo significa que es actividad pura de sí mismo, no hay distinción entre la acción y el producto de ésta, autogénesis absoluta, no hay resquicios de sujeto-objeto.

"El concepto de realidad es idéntico al concepto del hacer. Toda realidad es puesta en el yo: esto quiere decir que todo hacer es puesto en este, y a la inversa; todo en el yo es realidad: esto quiere decir que el yo es únicamente agente; es yo en la medida en que es agente; y en la misma medida en que no es agente, es no-yo". ${ }^{6}$

11 El segundo principio es "al Yo se opone absolutamente un No-Yo". ${ }^{7}$ Este principio, al igual que el primero, no puede ser demostrado ni derivado. Si el primer principio establece la autoposición absoluta del Yo como tal, Yo = Yo, el segundo establece que No-Yo no = Yo, vale decir, revela la misma identidad, sólo que negativamente; poner y oponer constituyen un mismo acto, sólo que el acto positivo es primero en un orden ontológico. De allí que ambos principios sean incondicionados en su forma, pero el No- 
Yo es condicionado en su materia porque queda determinado por lo que el Yo no es. No obstante, no debe entenderse esta oposición en términos excluyentes.

"No hay razón, pues, para poner la unidad absoluta en el ser o en la conciencia que se opone a él; tampoco para ponerla en la cosa o en la representación de la cosa. Hay que ponerla en el principio que acabamos de descubrir, principio de la unidad y de la inseparabilidad absolutas de ambos, que a la vez, como lo hemos visto también, es el principio de la disyunción de los dos". ${ }^{8}$

El tercer principio reza: "Tanto el Yo como el No-Yo son puestos absolutamente como divisibles". ${ }^{9}$ Estos dos principios, Yo y No-Yo se oponen mutuamente, de manera que es necesario encontrar cómo es que no se anulan mutuamente. La solución es que deben limitarse mutuamente, el Yo y el No-Yo se dan en función recíproca de limitación. Yo opongo en el No-Yo al Yo divisible un No-Yo divisible. De aquí surgen las dos esferas fundamentales de la filosofía: 1) El Yo se pone a sí mismo como determinado por un NoYo. 2) El Yo se pone a sí mismo como determinando al No-Yo. La primera proposición funda la filosofía teorética; la segunda, la filosofía práctica. Por eso, la dualidad de sujeto pensante y objeto pensado, como independiente de tal pensar, es una ilusión inherente a la razón teórica, de lo cual sólo puede liberarnos la razón práctica.

Se debe tener presente que, al igual que en Kant, pero radicalizado, para Fichte la parte práctica de la Doctrina de la Ciencia fundamenta y determina a la teórica. La filosofía teórica mostró cómo es posible la autolimitación del Yo, pero no pudo mostrar por qué ocurre. La proposición "el Yo se pone como determinado por el No-Yo"10 funda la parte teórica, por cuanto se trata del Yo como inteligencia y, por lo tanto, limitado. La proposición "el Yo se pone como determinando al No-Yo" funda la parte práctica ${ }^{11} \mathrm{y}$ establece al Yo como absolutamente puesto, por tanto como esencia (Wesen) ilimitada. Este Yo que se pone absolutamente es el mismo que el que se autolimita, pero el supuesto que late en el fondo es que el conocimiento es sólo medio para la acción y, por lo tanto, el Yo como inteligencia está subordinado al Yo práctico. El Yo es del todo e infinitamente activo, su actividad responde a un anhelo infinito de producir, esta actividad es el Yo mismo y ella es independiente de la posición de todo objeto. ${ }^{12}$

"Si el yo no se sintiera como anhelante, no podría sentirse como limitado, puesto que solamente por el sentimiento de anhelo el yo sale de sí mismo; sólo por este sentimiento en el yo y para el yo es por primera vez puesto algo que debe estar fuera de él". ${ }^{13}$

El objeto debe poder ser proyectado en la infinitud, por tanto, esta actividad sobre lo que se le resiste como su límite, tiene que proyectarse también en la infinitud, más allá de todo objeto posible y es ella misma infinita, es decir, es creadora.

El impulso a la determinación del No-Yo no se contenta con una pura determinación ideal, el Yo se autodetermina por este impulso a producir una realidad fuera de sí. ${ }^{14}$ Ahora bien, esta determinación no puede ser satisfecha plenamente porque el objeto no puede ser realizado como cosa por el Yo. Una determinación tal se llama anhelo; es un impulso hacia algo nunca plenamente realizado, que sólo se manifiesta por una necesidad, por un malestar, por un vacío que intenta ser colmado, el yo se vive menesteroso.

"Este anhelo es importante no solamente para la parte práctica de la Doctrina de la ciencia, sino para la Doctrina de la ciencia entera. Solamente por este anhelo el Yo es en sí mismo empujado fuera de sí; únicamente por este anhelo se revela en el Yo un mundo exterior". ${ }^{15}$ 
la cual el Yo se realiza. "El Yo sólo es puesto en movimiento por ese opuesto [No-Yo] para actuar; sin semejante primer motor exterior al Yo jamás habría actuado, y como su existencia sólo consiste en actuar, tampoco habría existido". ${ }^{16}$ De modo que la existencia y la misma conciencia no radica en el pensar, sino en el actuar. La dualidad sujeto-objeto, Yo y No-Yo, propone la dificultad de la síntesis de ambos. En términos de Schelling, es necesario explicar, por una parte, cómo el sujeto llega a ser objeto, es decir, conoce, tal habría sido el centro de atención de la filosofía clásica. Pero esta síntesis no es suficiente, es necesario explicar también, por otra parte, cómo el objeto llega a ser sujeto. "El fundamento real y el fundamento ideal son en el Yo uno y lo mismo, y aquella acción recíproca entre el Yo y el No-Yo es, a la vez, una acción recíproca del Yo consigo mismo". ${ }^{17}$

cómo el No-Yo llega a ser Yo, y este tránsito, movido por un anhelo de totalización, revela que el límite entre uno y otro es puesto por el Yo, si así no fuera, el Yo jamás podría moverlo. El límite último, inalcanzable, de esta actividad sería la absoluta subsunción del No-Yo por parte del Yo. La cultura sería entonces la forma como el Yo, sin salir de sí mismo, no obstante, se trasciende en una tarea infinita por la que la realidad cultivada se transforma en topos propiamente humano. Pero es necesario tener presente que este lugar, así construido, es el espacio común que permite un encuentro interior de los seres humanos entre sí. La cultura es el hábitat en el que se comunica la subjetividad objetivamente, por cuanto la objetivación de sí en la obra crea un ámbito de encuentro que no se limita a la plaza-mercado, al lenguaje, a la técnica o al arte, sino que hominiza, porque es expresión de la misma actividad del Yo en el No-Yo, de este modo, como sostiene Fichte, un Yo absolutamente clausurado sobre sí, que volviera su actividad sobre sí mismo, ni siquiera podría decir Yo. La cultura es expresión de la libertad, es la misma actividad del Yo como ejercicio de sí mismo. En palabras de Fichte: "Cultura significa ejercitación de todas las fuerzas para el fin de la libertad completa, de la entera independencia de todo lo que no somos nosotros 
mismos, de lo que no es nuestra pura mismidad". ${ }^{18}$ Pero la obra misma de esta actividad se realiza en un mundo suprasensible, en el que los fines individuales han de ser subordinados a la universalidad de la razón misma.

"Esta cultura para la libertad es el único fin posible para el hombre, en cuanto parte del mundo sensible, el fin sensible más elevado que, sin embargo, no es para él un fin en sí mismo sino último medio para alcanzar su más elevado fin espiritual, la completa coincidencia de su voluntad con la ley de la razón. Todo lo que el hombre hace y todo aquello a lo que aspira o bien ha de ser considerado como medio para este fin último en el mundo sensible, o bien es una aspiración sin meta alguna, una aspiración irracional". ${ }^{19}$

20 Se debe recordar, a este respecto, que el carácter universal de la ley de la razón significa la superación y abandono de todos los intereses individuales. El ser humano yerra radicalmente cuando cree ir simplemente en pos de sí mismo, ya que lo que encuentra al final jamás podrá de verdad satisfacer su verdadero anhelo.

21 Así, pues, la cultura convierte de alguna manera lo exterior en interior, y la primera fuente de esa conversión, que permite que la obra trascienda los límites subjetivos del individuo, incluso también como condición de posibilidad del mercado mismo, es el pacto que da origen a la sociedad política. No obstante, este pacto supone, como algo anterior, el reconocimiento del otro como fin en sí mismo. La comunidad política es el topos originario de la cultura, cuya expresión primaria es la conversión de la naturaleza en recurso, de los recursos en bienes y, si se quiere, de los bienes en objetos de transacción. Pero todo lo anterior sólo se puede realizar, y necesariamente, en la medida que se ha previamente construido un lugar común de encuentro, una plaza, en la que convergen quienes han pactado previamente la paz. Para ello se establece, como se sabe, una estructura de derecho y dispositivos que la garanticen, pero teniendo presente que estos dispositivos no tienen otro sentido que la libre expresión de sí $^{20}$ aunque, reiterando la tesis de Rousseau, Fichte afirma que en este contrato social cada miembro renuncia a algunos de sus derechos alienables a condición de que los otros renuncien también a algunos de los suyos ${ }^{21}$, con el propósito de vivir en libertad sin temor.

Pues bien, el espacio virtual parecía la tierra soñada del buen salvaje de Rousseau, plena libertad, ausencia de un poder central que fuera capaz efectivamente de coerción, un territorio donde el ser humano se encuentra con sus semejantes en un plano de real igualdad. Sin embargo, como señala el ginebrino en Acerca del origen de la desigualdad entre los seres humanos, "el primer hombre que dijo esto es mío y estableció una cerca, sembró la discordia entre los seres humanos", y comenzó así la guerra de todos contra todos sin que nadie tuviera ya segura su vida y su hacienda, lo cual obligó a quienes hasta ese momento vivían en completa libertad, a establecer un pacto que los obligaría a todos, dando origen a una estructura de poder, asociado necesariamente a un monopolio de la fuerza, sistemas de sanción y dispositivos de control. Sin embargo, como decíamos, la propiedad que está en juego en el discurso de los piratas es una propiedad simbólica que requiere de un estatuto particular para su defensa, y este estatuto, en la medida que se trata de bienes inmateriales, no defiende la privación del bien mismo de su poseedor legítimo por parte de usurpadores, sino sólo el carácter de objeto comerciable.

Por otra parte, una de las características fundamentales del derecho es su territorialidad, es decir, dado que la comunidad política surgiría de un pacto y es, desde esta perspectiva, artificial, se debe reconocer la posibilidad de otros artificios posibles, 
fundados en otros esquemas y estructuras de convivencia, que ocurren en otros territorios. Ahora bien, el hypertopos es un nuevo mundo, un continente que no responde en absoluto a las categorías propias de la territorialidad física. De modo que cabe preguntar si no es necesario establecer un nuevo pacto, en el cual no se pretenda meramente una "absolutización metafísica del orden geopolíticamente establecido ${ }^{22}$ sino, precisamente, intentar un reconocimiento de todos en una real perspectiva de igualdad fraterna. Hasta ahora los débiles que están más allá de las fronteras, en otros territorios y en otras culturas han sido objeto de diversas formas de caridad, lo cual está bien, pero ahora lo que se pide es el reconocimiento de un derecho. Por ello, un pacto de tal naturaleza no puede simplemente consistir en trasponer la estructura y los dispositivos territoriales al nuevo espacio, no sólo porque se arriesga su constante violación impune, y las leyes fácilmente violables y difícilmente coercitivas no son buenas leyes, sino sobre todo porque lo que está en juego allí es la universal disposición pública de la cultura. Más aún, una simple territorialización del hypertopos significaría de hecho que sólo los Estados fuertes podrían imponer sus normas sobre los más débiles, ya que los Estados débiles, por lo mismo, serían incapaces de exigir el cumplimiento del presunto pacto a los fuertes que se negaran a aceptarlo.

Fichte, con la retórica que caracteriza sus escritos populares, dice dirigiéndose al Príncipe:

"Admitiendo que hubieseis tenido el derecho a prometer: yo no quiero compartir con nadie mi pan, [...] ¿Queréis cortar el más bello vínculo que une a un hombre con otro hombre y que hace que un espíritu se desborde en otro espíritu? ¿Queréis privar a la humanidad del más digno de los comercios, del dar y recibir libre y gozosamente lo más noble que ella posee?". ${ }^{23}$

Si bien Fichte se refiere a la libertad de pensamiento, tal vez esto se pueda ampliar sin pérdida de sentido a los productos del espíritu que conservan su peculiar naturaleza. Se podrá, sin duda, afirmar que el espacio económico es de suyo virtual y simbólico y que, por lo tanto, la territorialización del hypertopos no puede sino responder a la misma lógica. Si este nuevo espacio requiere correspondientemente de un nuevo pacto, entonces la cuestión es la de fijar qué derechos son los que se han de proteger y si están en cuestión derechos inalienables o no. Lo anterior porque:

"si fuese posible moralmente un contrato de este tipo, si la sociedad tuviese el derecho a exigir tal compromiso y sus miembros el derecho a prometer su cumplimiento, ¿no serían alienados en tal contrato derechos inalienables del hombre, cosa que no puede ocurrir en ningún contrato, a no ser que se convierta en ilegítimo y nulo?". ${ }^{24}$

Como ocurre en todo conflicto de derechos, cabe preguntar si acaso está en juego un derecho inalienable, por una parte, y si no es así, si hay uno que sea primario respecto de otro.

Por otra parte, se debe tener presente que para Fichte, como también para Kant, la razón práctica constituye la plena realización de lo humano. Ahora bien, la exigencia de universalidad del imperativo categórico se la puede interpretar en el sentido de que la persecución del propio interés, vale decir, el egoísmo, es la fuente originaria de todo mal. "El egoísmo es la raíz de todas las depravaciones". ${ }^{25}$ En este sentido, se debe educar en la solidaridad y la preocupación por el otro, ya que sólo de esta manera es posible la constitución de una sociedad que sea efectivamente viable. Se debe lograr que "ningún hombre tome como ajeno a él el destino de cualquier otro miembro, unidad que debe y tiene que surgir si es que no queremos perecer totalmente" ${ }^{26}$ En este sentido Fichte 
establece una distinción entre Estado y Sociedad, el Estado es la institución coactiva, basado en el ejercicio de la fuerza, la sociedad es una organización que surge de la libertad de los sujetos y está basada en la colaboración. El Estado es necesario en razón de la debilidad e imperfección de los seres humanos, que muchas veces requieren de coacción para orientarse al bien común y desatender sus intereses individuales.

Fichte, en Las características fundamentales de la época actual ${ }^{27}$ había propuesto cinco épocas históricas que se suceden teleológicamente, y había afirmado que en ese momento se encontraban en la tercera, la que caracteriza, en otro lugar, del siguiente modo: "[época] que ha hecho del mero interés material el móvil de todas sus emociones e impulsos vitales, que se entiende y concibe a sí misma de manera perfecta sólo dentro del mencionado móvil y que, al comprender su ser de esta manera clara, se fundamenta en su esencia vital y se asegura de modo inamovible". ${ }^{28} \mathrm{Si}$ bien en Discursos a la nación alemana, cree que esta época "se ha consumado y aniquilado por completo", eso parece ser más la expresión de un deseo que una realidad. No obstante, la solución que propone para volver a levantar a la cultura [Bildung] alemana de su decadencia es enseñar a "amar lo bueno, en cuanto tal, y no por la utilidad que nos pueda reportar." 29

De este modo, la cultura no consiste meramente en el proceso infinito por el cual el Yo vuelve el No-Yo hacia sí, ya que esto deja abierto el problema del sentido, porque el Yo puede operar su obra de modo intrascendente, es decir, egoístamente, con lo cual no realiza una verdadera cultura, porque así todo queda convertido de este modo en mercancía, según la utilidad que reporta, mercancía de la cual su autor, o quien haya comprado la autoría, se sirve para su propio beneficio; y el beneficio que pueda reportar a los demás, entendido como externalidades positivas, es lo que se transa en el mercado. Sin embargo, se podría aducir que no hay gran diferencia, en lo que a propiedad se refiere, entre un bien material y uno inmaterial o sólo virtual, dado que ambos son producto de un trabajo y de un ingenio, de modo que si bien lo que se transa de hecho es el producto, lo que se paga es el valor del trabajo y del esfuerzo, los que legítimamente merecen, no sólo un reconocimiento moral, sino una recompensa económica. En de Fichte: "La transformación de las cosas por la fuerza propia (formación) es el verdadero fundamento del derecho de la propiedad". ${ }^{30}$

Y, por otra parte, se podría aducir que el monto de tal recompensa sólo lo podría fijar el mercado, ya que es imposible establecerlo a priori. Incluso se podría sostener que un presunto "valor en sí" contiene la misma contradicción que la "cosa en sí", entendido ahora como realidad trascendente a todo estimar humano. Por otra parte, casi todas estas obras de la cultura tienen el carácter de únicas, como único es el Hamlet de Shakespeare o Los comedores de patatas de Van Gogh.

31 Fichte, en Algunas lecciones sobre el destino (o misión) del sabio sostiene que el destino del sabio es un destino social por excelencia ${ }^{31}$, esta misión es responde a un mandato moral, que es expresión de una necesidad propia de toda comunidad política. ${ }^{32}$ Pero las determinaciones empíricas de nuestro Yo dependen, en su mayor parte, de algo que está fuera de nosotros, pero como la unidad del Yo tiene el carácter de un mandato, éste debe obrar inmediatamente sobre las cosas, "el hombre debe tratar de modificarlas y ponerlas en armonía con la pura forma de su Yo". ${ }^{33}$ Ahora bien, esta acción del Yo sobre el no-Yo constituye la cultura. Pero este cultivo del No-Yo no tiene un sentido egoísta, no puede tenerlo como mandato moral, es más, "el hombre está destinado a vivir en comunidad, debe vivir en comunidad, no será un hombre totalmente completo y caerá en contradicción consigo mismo si vive aislado" ${ }^{34}$ Además, la cultura es "el 
último y más perfecto medio para realizar el fin humano"35 porque está ordenada a la realización del reino de los fines, reino en cuya consecución está comprometida la humanidad entera. Y para esto es necesario que las deficiencias de unos sean atendidas por otros cultivándolos, de modo que la razón cuida de que cada individuo reciba mediatamente de manos de la sociedad la cultura toda completa que no pudo obtener inmediatamente de la naturaleza. ${ }^{36}$ Así, pues, cada ser humano en su esfera de capacidad, pero fundamentalmente los sabios, se han de comprometer moralmente en el cultivo de la comunidad toda, sin exclusiones.

Quisiera terminar con una larga cita de Fichte, cuya retórica no es sino expresión de su carácter exhortativo:

"Quienquiera que seas, cualquiera puede decir que por el hecho de poseer semblante humano eres un miembro de esta gran comunidad; que, aun cuando mi acción tenga que atravesar innumerables miembros, yo influyo sobre ti y tú también influyes sobre mí; que nadie que lleve el sello de la razón en su rostro, por muy groseramente que esté impreso, carece de importancia para mí. Y, sin embargo, yo no te conozco a ti ni tú a mí. ¿Oh, tan cierto como que nuestra vocación común es ser buenos y ser cada vez mejores, es que llegará un tiempo (aun cuando hayan de transcurrir millones y billones de años, pues, ¿qué es el tiempo?) en que te arrastraré a mi círculo de acción, pues mis beneficios se cruzarán con los tuyos y nuestros corazones estarán enlazados por el más bello vínculo del libre dar y recibir mutuo". ${ }^{37}$

\section{Bibliografía}

DUQUE, F. (2006) ¿Hacia la paz perpetua o hacia el terrorismo perpetuo? Madrid: Círculo de Bellas Artes.

ZD. FICHTE, J. G. (1964), Zurückforderung der Denkfreiheit von den Fürsten Europens, die sie bisher unterdrückten. Fichte-Gesamtausgabe der Bayerischen Akademie der Wissenschaften, I/1. R. Lauth et al. (eds.). Stuttgart-Bad Cannstatt, FrommannHolzboog, 1964.

VND. FICHTE, J. G. (1970) Versuch einer neuen Darstellung der Wissenschftaslehre. FichteGesamtausgabe der Bayerischen Akademie der Wissenschaften, I/4. R. Lauth et al. (eds.). Stuttgart-Bad Cannstatt, Frommann-Holzboog, 1970.

GWL. FICHTE, J. G. (1965) Grundlage der gesammten Wissenschaftslehre. FichteGesamtausgabe der Bayerischen Akademie der Wissenschaften, I/2. R. Lauth et al. (eds.). Stuttgart-Bad Cannstatt, Frommann-Holzboog, 1965.

FDC. FICHTE, J. G., (1975) Doctrina de la Ciencia. Traducción de Juan Cruz Cruz. Buenos Aires.

EWL. FICHTE, J. G. (1966) Grundriss des Eigenthümlichen der Wissenschaftslehre in Rücksicht auf das theoretische Vermögen. Fichte-Gesamtausgabe der Bayerischen Akademie der Wissenschaften, I/3. R. Lauth et al. (eds.). Stuttgart-Bad Cannstatt, FrommannHolzboog.

WL 1804². FICHTE, J. G, (1804) Wissenschaftslehre 1804. Fichte-Gesamtausgabe der Bayerischen Akademie der Wissenschaften, II/8. R. Lauth et al. (eds.). Stuttgart-Bad Cannstatt, Frommann-Holzboog.

BB. FICHTE, J. G., (1845) Beiträge zur Berichtigung der Urtheile über die französische Revolution. Johann Gottlieb Fichtes sämtliche Werke, VII. H. Fichte (ed.). Berlin: Veit und Comp. 
41

\section{NOTAS}

1. Citado por Wikipedia, en.wikipedia-org/wiki/Propiedad_intelectual

2. Cf. VND, GA I/4: 241

3. VND, GA I/4: 186

4. GWL GA I/2: 259; FDC: 46

5. Cf. EWL, GA I/3: 176

6. GWL, GA I/2: 296-297; FDC: 86

7. Cf. GWL, GA I/2: 264 ss.; FDC: 52 ss.

8. WL $1804^{2}$, GA II/8:12-13; FDC: 50

9. GWL, GA I/2: 270-271; FDC: 58

10. GWL, GA I/2: 328; FDC: 116

11. Cf. GWL, GA I/2: 285; FDC: 74

12. WL 1804': 205; FDC: 258

13. GWL, GA I/2: 431; FDC: 215

14. Cf. GWL, GA I/2: 426; FDC: 210

15. GWL, GA I/2: 431; FDC: 215

16. GWL, GA I/2: 411; FDC: 192

17. GWL, GA I/2: 412; FDC: 193

18. BB, FSW, VI: 86

19. BB, FSW VI: 89

20. Cf. ZD, GA I/1: 168; RLP: 12

21. Cf. ZD, GA I/1: 174; RLP: 17

22. Duque 2006: 22

23. ZD, GA I, 1: 177; RLP: 21

24. ZD, GA I/1: 182; RLP: 31

25. DNA: 18

26. DNA: 14

27. GgZ, GA I/8: 197 ss.

28. DNA: 11

29. DNA: 33

30. BB, FSW VI: 117

31. BG, GA I/3: 55

32. BG, GA I/3: 57. SW, VI: 295 ss. y 297

33. $B G, G A I / 3: 30-31$ 
34. BG, GA I/3: 37

35. BG, GA I/3: 31. DS: 307

36. Cf. BG, GA I/3: 45

37. BG, GA I/3: 41; DS: 321

\section{RESÚMENES}

This paper analyses the problems of virtual space in relation to culture and intellectual property, following the "pirate" movement. I will use the Fichtean categories to determine what culture and its role in the achievement of human purpose are. In this sense, the Fichtean conception of "wise", his destination or mission and his subordination to the common good can serve to understand not only the ultimate sense of knowledge and culture, but also their solidary sense as promoting the realisation of the kingdom of ends.

ÍNDICE

Keywords: Culture, pirate movement, intellectual property, wisdom

\section{AUTOR}

\section{HUGO OCHOA}

Pontificia Universidad Católica de Valparaíso 